\title{
Neighbourhood Quality Satisfaction in Planned Areas in Port Harcourt Municipality
}

\author{
Ebiwari Wokekoro \\ Department of Estate Management, Rivers State University of Science and Technology, PMB 5080, Port Harcourt
}

\begin{abstract}
This study assessed residents' satisfaction with neighbourhood quality in two planned areas of Port Harcourt, Nigeria. The study ascertained residents' satisfaction with neighbourhood attributes, sanitation attributes and residential quality of life. Neighbourhood attributes were studied in situ without experimental manipulation and at one period in time, i.e. the study adopted a passive-observational research design. The study utilized both secondary and primary data sources. Primary data was collected using face-to-face administration of a largely pre-coded household questionnaire, to a probability sample of 171 respondents, drawn from the 2 neighbourhoods. Data analysis was based on responses from 171 questionnaires retrieved and the univariate analytical method was adopted. The study found, that residential quality of life in the planned areas was moderate. Port Harcourt. The study further revealed that some residents were dissatisfied with their residential conditions such as electricity supply, water supply and waste collection and disposal while a high percent were satisfied with safety of life and properties. The study further revealed that 25.6\%of the residents in Old GRAwere pleased with their residential quality and $14 \%$ of the residents in D-Line were pleased with their residential quality. The study concluded that in the provision of public infrastructure and services, the perceptions and preferences of the beneficiaries/target population must be seriously taken into account to achieve user satisfaction. The study recommended that government should take advantage of funds available in the National Urban Development Bank, assistance from international development agencies and through private-public-partnership (PPP) arrangement for adequate provision and maintenance of infrastructure and amenities.
\end{abstract}

Keywords: Neighbourhood, quality, satisfaction, planned areas, Port Harcourt

\section{Introduction}

Quality of life and quality of the urban environment throughout the world are issues of concern for researchers as well as planners, policy makers and urban residents (Mridha and Moore, 2011). The search for quality of life, particularly in the city, has occupied post-industrial and predominantly urbanized societies (such as the United States of America and Great Britain) for more than 40 years. This has led to initiatives to measure the concept in urban areas (Senecal, 2002) who argued that, the concept of quality of life, as applied to the urban environment, is usually understood in two ways. The first concerns the living environment and involves the patterns of advantages, disadvantages and opportunities that affect each citizen through accessibility to services, facilities and amenities. Other elements of the living environment include economic vitality and social equity, which encapsulate an infinite number of specific issues, notably, the quality and affordability of housing. The second approach relates to the natural environment in urban spaces. This approach holds that such factors as air, water, soil quality; and the amount of available green space affect the ways we live (Senecal, 2002).

Senecal (2002) added that other aspects that may be used to identify quality of life include aesthetic value, satisfaction with one's home, and patterns of governance and there are also issues of perception that take into account people's experiences in the city, the routes they travel, and the sensory quality of their surroundings.

Nowadays, cities have become the target of quality of life measurement since they exhibit contemporary culture, ranging from technological development to social progress. Indeed, the process of urban planning and management is aimed at raising quality of life, especially with regard to improvement of facilities and services that fulfil socio- economic needs such as education, health, housing, entertainment, and safety (Discoli, et. al., 2006).

Port Harcourt, one of Nigeria's major cities, has been experiencing rapid urbanization since its inception in 1913. The city has grown from 5,000 persons in 1915, two years after its inception, to 79,634 in 1953, and to 179,563 in 1963 (Ogionwo, 1979). The 1991 census gave the city's population as 440,399 and the 2006 census fixed it at 541115. The population was projected from the census figure of 2006 to a projected population of 963,373 in 2010 assuming linear growth and an average annual growth rate of $5.2 \%$. This level of population growth has meant considerable spatial expansion, which has engulfed once distant villages on the urbanperiphery, to the extent that they can no longer be distinguished but have become part of the urban fabric (Wokekoro and Owei, 2006).

Urban infrastructure and services have failed to keep pace with this growth. In addition to rising urban poverty, there is a worsening of urban environmental problems. Such challenges as poor solid waste management, uncontrolled housing and neighbourhood development, flooding, traffic congestion, poor state of the urban physical environment and rising crime rates have been documented (Ugwuorah, 2002; Mchi, 1997). More recently, Obinna, Owei and Mark (2010) have also noted the deplorable housing, inadequate space, and absence of basic services in the informal settlements of the city.

This state of affairs triggered the desire to measure residents' satisfaction with neighbourhood quality of life in planned neighbourhoods in Port Harcourt Municipality. The aim was to demonstrate the nature and magnitude of deficient conditions in the planned areas in the municipality and propose appropriate measures to deal with them. Spatially, the study covered two planned neighbourhoods in

\section{Volume 6 Issue 1, January 2017




\section{International Journal of Science and Research (IJSR) \\ ISSN (Online): 2319-7064 \\ Index Copernicus Value (2015): 78.96 | Impact Factor (2015): 6.391}

Port Harcourt Municipality; that is, Port Harcourt Local Government Area (PHALGA), namely: Old GRA and D Line.

\subsection{Goal and Objectives of the Study}

The goal of this study is to assess residents' satisfaction with neighbourhood quality in two planned neighbourhoods in Port Harcourt Municipality.

The objectives of the study are to:

1) Ascertain residents' satisfaction with neighbourhood attributes;

2) Ascertain residents' satisfaction with sanitation attributes.

3) Obtain Neighbourhood Satisfaction Index (NSI)

4) Ascertain the variables that are most important to residents in improving residential quality of life in Port Harcourt.

\section{Background Information about the Study Area}

Port Harcourt, capital city of Rivers State, Nigeria, lies 40 $\mathrm{km}$ up the mouth of the Bonny River, in the Niger Delta.
Originally known as Igwu-Ocha" by the indigenous Ikwerre, was founded in 1913 by the British in an area traditionally inhabited by the Ikwerre and the Okrika Ijaw. It was named after Viscount Harcourt, then British Secretary of State for the Colonies. The initial purpose of the port was to export the coal, which geologist Albert Ernest Kitson had discovered in Enugu in 1912 (Ogionwo, 1979).

It is one of Nigeria's fastest growing cities. The average annual growth rate of Port Harcourt between 1963 and 2010 has been computed to be $5.2 \%$. The growth of Port Harcourt is tied to the social and economic history of the country. Figure 1.1 is a map of Port Harcourt Municipality showing the study locations.

The city is a major educational, administrative, and industrial centre, and is regarded as the oil capital of Nigeria, since it hosts most of the nation's multi-national oil and gas exploration and production companies, two refineries, petroleum-related service companies, as well as a fast expanding commercial sub-sector (Wokekoro and Owei, 2006).

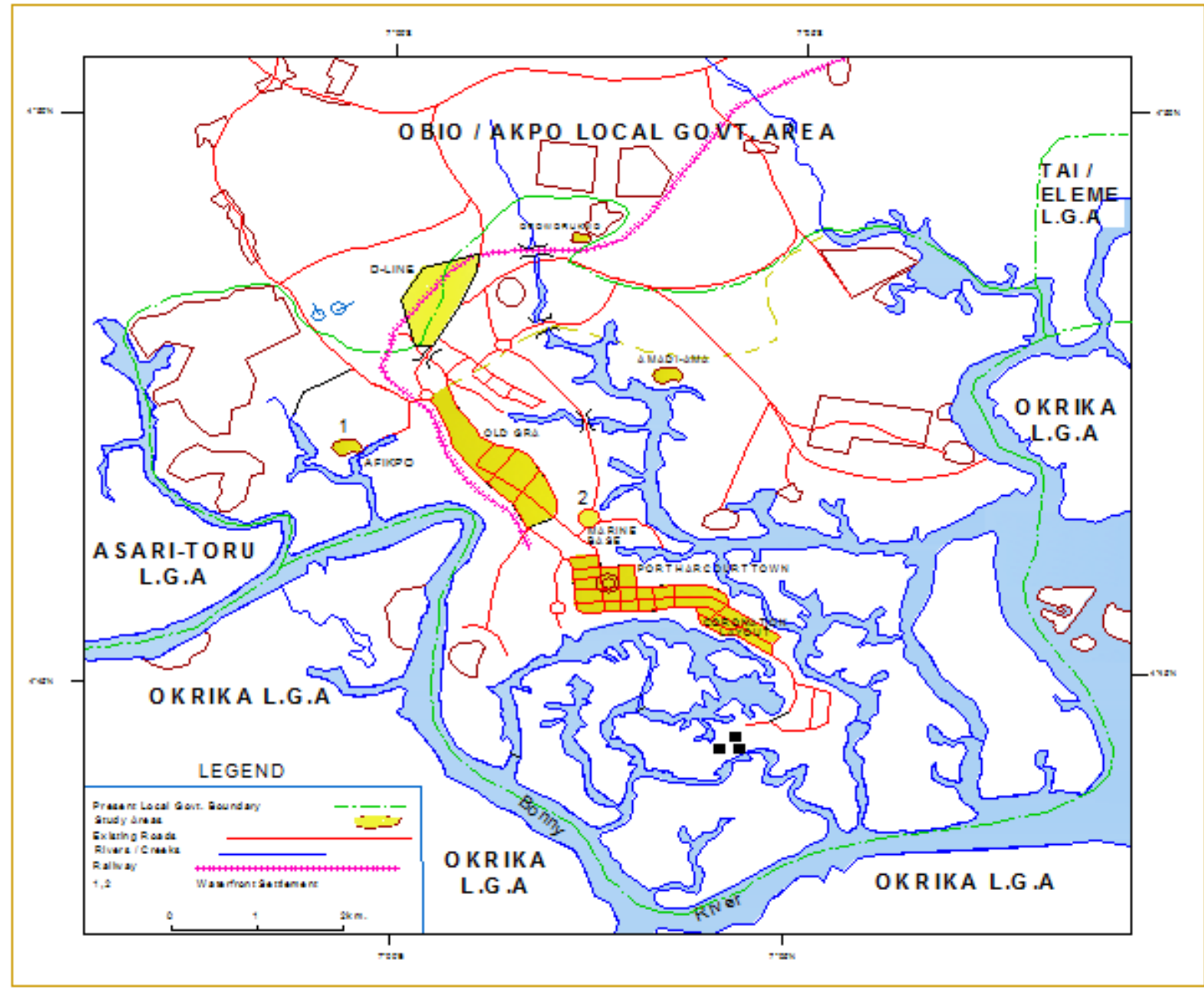

Figure 1.1: Port Harcourt Municipality Showing the Study Areas 


\section{International Journal of Science and Research (IJSR) \\ ISSN (Online): 2319-7064}

Index Copernicus Value (2015): 78.96 | Impact Factor (2015): 6.391

\subsection{Review of Relevant Literature}

The meaning of the phrase - rban quality of life" differs a good deal as it is variously used but, in general, it is intended to refer to either the conditions of the environment in which people live (air and water pollution, or poor housing, for example), or to some attribute of people themselves (such as health or educational achievement) (Pacione, 2003). The concept, Quality of Life, encompasses the basic conditions of life, including adequate food, shelter, and safety, as well as tife enrichers", which are based on the individual's values, beliefs, needs and interests (WHO-IACCID, 2000).Measuring quality of life means that we value quality within people's lives and that we want to maintain and/or enhance the things that already, or could, add quality to people's lives. It also infers that we want to take action to improve the things that currently detract from quality of people's lives (WHO-IACCID, 2000).

Lotfi and Solaimani (2009) stated that a number of researchers have reviewedliterature on Quality of Life (QOL) and there is general agreement that a meaningful definition of QOL must recognize that there are two linked dimensions to the concept, namely a psychological one and an environmental one.

There are two sets of indicators for measuring quality of life with which most of the researchers have agreed. The first set comprises objective indicators which refer to the objective and visible aspects of urban life and are defined by different elements, for example the number of hospitals in a city, unemployment rate, the volume of crime and the area of urban green spaces. The second set comprises subjective indicators which try to measure and quantify the citizens' satisfaction with those objective attributes (Lotfi and Solaimani,2009).

QOL is concerned with people's welfare. It is defined as something that makes life better. (Discoli et. al., 2006). A number of domains of QOL (well-being) have been identified in the international quality of life literature. For example, University of Oklahoma School of Social Work (www.gdrc.org) identifies the following: family and friends; work; neighbourhood/shelter; community; health; education; and spiritual. Each domain contributes to one's overall assessment of the QOL as a whole. The focus here is on the residential environment or what is referred to above as Neighbourhood/Shelter. Various researchers have addressed this dimension.

\subsection{Research on Residential Quality of Life}

Salau (1986) examines the variations in the quality of life at the relatively neglected inter-urban scale in a developing nation. Based on a sample survey of 3,800 heads of households in Nigeria cities ranked into three categories: large, medium and small, the study found that level of living is related to city size, with the residents of large cities having a higher quality of life than those in the medium and small cities.

Giannais (1996) used a structural approach to hedonic equilibrium model to obtain a quality of life ranking of six cities in Southern Ontario, Canada namely: Guelph, Kitchener, London, Sarnia, St. Catharine, and Windsor and found that residential quality of life is a function of housing and neighbourhood characteristics (number of rooms, age of the house, crime rate, air quality, and mean annual temperature). The model was estimated using census tract data for the six cities. The study revealed that each of the six cities provides a different QOL distribution to its residents.

Hall, et.al.(2008) considered valuation of amenities in urban neighbourhoods and satisfaction with both those neighbourhoods and life in general. First, rents were used to estimate neighbourhood amenities price in San Jose, which explained 39 percent of the standardized variation in rents. Some districts ranked very high in housing characteristics but poorly in neighborhood amenities, while others ranked poorly in housing characteristics but high in neighborhood amenities, suggesting that policy measures might reduce inequality in urban areas through improving neighborhood amenities.

Second, the paper explored differences in the valuation of amenities by calculating prices in different urban areas. In more sparsely populated urban areas, distance to national parks was less important, but distance to primary roads became more important. Finally, housing and safety satisfaction represented the key components of life satisfaction.

Coker, et al. (2007) carried out a survey of housing quality and neighbourhood environments in Ibadan City, Nigeria. The study evaluated the housing infrastructure and identified those areas where there was a likelihood of future incidences of disease and epidemics. Based on existing demographic and land use characteristics, the city could be divided into high, medium and low-density zones. Penalty scoring, rather than positive scoring, was used to assess the conditions and quality of houses and the neighbourhood environment in each of the zones. Houses in the high-density area had the worst property and environmental characteristics followed by houses in the medium-density area. Based on housing condition alone, approximately half of all the dwellings surveyed $(n=172)$ in the three zones were categorised as either substandard or unfit for human habitation. Based on neighbourhood environment, none of the high and mediumdensity housing areas and only one of the low density areas attained the good-scoring grade. This is attributed in part to the many residents who are polygamists. The houses are overcrowded with perhaps up to eight persons per room and to tenant abuse by internal conversion to increase the occupancy rate. More than half of the houses surveyed have at least one or more major defect. Recommendations include government directed infrastructure improvements; a regeneration-drive by private investors with possible displacement of residents from the high-density zone to new towns; a vigorous programme of housing and health education; enhanced collaboration between stakeholders to develop enforceable standards for existing housing stock and future builds.

The primary objectives of the Seattle Housing Authority research were to evaluate the effectiveness of SHA's operations by interviewing 325 SHA residents currently 


\section{International Journal of Science and Research (IJSR) \\ ISSN (Online): 2319-7064}

Index Copernicus Value (2015): 78.96 | Impact Factor (2015): 6.391

residing in SHA operated housing. Variables tested in this research included: assessing residents' satisfaction level with housing, other indoor spaces in the community and outside grounds; measuring the perception of safety and security within each resident's neighbourhood; examining satisfaction with resident treatment, maintenance and management staff ; evaluation of residents satisfaction with the home inspection process ; analyzing the perceived quality and availability of social services; testing the satisfaction and identifying the needs of residents Statistical Significance Statistical significance explains the differences among groups and variables. What this means is that when a value, if found to be significant (a p value of .05 or less) exists, that the groups involved have significantly different opinions about the particular subject. For instance, where the value is not significant, it reflects that the group, as a whole has a similar opinion about the variable being tested. This research revealed that SHA residents are extremely satisfied with all the variables examined. These findings were truly remarkable; in most satisfaction surveys results do not contain nearly the same degree of satisfaction as can be found among SHA residents. (Hebert Research, 2009).

Mridha and Moore (2011) explored the quality of life(QOL) in six major residential areas in Dhaka, Bangledesh, as part of a citywide research program examining residential environments. Their study examined how people assess their lives and life experiences and, in particular, their satisfactions with housing and neighbourhoods. Findings indicate the importance of the holistic socio-physical neighbourhood as a major contributor to residential satisfaction in medium- rise and high-rise housing in Dhaka. Other findings revealed that specific socio-physical features of the neighbourhood and community influence overall life satisfaction more than physical design features of dwellings.

This study focuses on the comparison of satisfaction level within different age groups in the core area of Ibadan, Oyo state, Nigeria. Based on the assumption that age of residents influences neighbourhood satisfaction and that this satisfaction is in varying degrees between different age groups, nonparametric test was used to examine the differences. Result showed that age of residents was significantly related to neighbourhood satisfaction. An analysis that focused on the differing age group satisfaction with the neighbourhood showed significant differences. However differences were more significant below 20 years age bracket and 61-70 years (Adewale et. al, 2015).

Housing is an essential tool by which most individual measure quality of life. This study assesses residents' satisfaction in public housing estates in Osogbo with a view to suggest strategies to improve residents' life quality having examined housing conditions and adequacies of existing infrastructure. Residents' socio-economic characteristics, satisfaction of housing conditions and neighbourhood qualities were obtained from six (6) public housing estates using structured questionnaires administered on 312 household heads. Residents' assessments of their housing conditions and satisfaction of their housing and neighbourhood qualities were collated using Likert scale ratings. Mean Weighted Values (MWV) were computed upon which comparisons were based. The study reveals that the entire study area were poorly equipped with infrastructure, only $56.6 \%$ of expected infrastructure were found in at least one of the housing estates. The study recommends improvement in infrastructure provision through Public- Private Partnership Initiatives (PPPI), resuscitation of Estate Management Board and the use of upgraded local building materials to enhance improved neighbourhood qualities, employment creation and forestall the volatility of movement within and outside the housing estates (kehinde et.al, 2015).

Novianto et.al (2016) conducted a study on the method of evaluating the residential environment in terms of neighborhood facilities and urban planning. Subjective evaluations through questionnaire survey were performed in order to grasp the residents' behaviours and preferences. In 2013, questionnaires were distributed to more than 3,000 households of younger families located in Kitakyushu City, Northern Kyushu Island, Japan. In this study, the results from questionnaires were analysed with the statistical method .The results revealed that almost all the respondents were still dissatisfied with safety, even though the safety level score has increased during 10 years and more than $60 \%$ of households realized their comprehensive wish on living condition, which means the target of residential environment plan and design are nearly achieved.

\section{Research Method}

The target population is composed of household members residing in the planned neighbourhoods. This study adopted the stratified multistage sampling technique (Kish, 1965). The sampling stages are given below:

Stage 1: Selection of neighbourhoods from the planned neighbourhoods (see selected neighbourhood in Table 1).

Stage 2: Listing of buildings and households from the selected neighbourhoods.

Stage 3: Selection of households to be studied from the chosen

Neighbourhoods; and

Stage 4: Selection of household respondents in the households to be studied, preferably heads of households, since they are usually the most knowledgeable about neighbourhood attributes

To achieve a representative sample of households in each neighbourhood, Yamane (1967) formula (given below) was applied.

$$
r=\frac{N}{1+N(\theta)^{2}}
$$

Where $\mathbf{n}$ is the sample size, $\mathbf{N}$ is the population size, and $\mathbf{e}$ is the level of precision (here set at 10\%). Following determination of the sample size, the systematic sampling method (Kish, 1965) was used to select the households to be questioned from the ordered list of population elements). 
International Journal of Science and Research (IJSR)

ISSN (Online): 2319-7064

Index Copernicus Value (2015): 78.96 | Impact Factor (2015): 6.391

Table 1: Sampling Details

\begin{tabular}{|c|c|c|c|c|}
\hline Name of Stratum & Name of Neighbourhood & Total No. of Buildings & Total of No. Households (N) & Sample Size * \\
\hline \multirow{2}{*}{$\begin{array}{c}\text { Planned } \\
\text { Neighbourhoods }\end{array}$} & Old GRA & 214 & 358 & 78 \\
\hline & D- Line & 80 & 1,412 & 93 \\
\hline \multicolumn{2}{|c|}{ Total } & 1,017 & 1,770 & 171 \\
\hline
\end{tabular}

*Using the Taro Yamane Formula @ 10\% Level of Precision

This study adopted a passive-observational research design. Passive-observational research designs pertain to studies where there has been no prior treatmemt", intervention, or manipulation of subjects. The data was collected through a household questionnaire and utilized univariate analysis. This study formed one index -Neighbourhood Satisfaction Index (NSI), using subjective neighbourhood attributes.

\section{Results and Discussion}

This section presents results of analyses carried out in the course of the study. One hundred and seventy-one (171) household questionnaires were administered and 171 retrieved, i.e. a response rate of $100 \%$. Analysis was therefore based on 171 households in the two planned neighbourhoods.

\subsection{Satisfaction with Neighbourhood Attributes}

Table 2 displays residents' satisfaction with selected neighbourhood attributes in the two planned neighbourhoods. Table 2 indicated that over 40 percent (48.7\% in Old GRA and $45.1 \%$ in D - Line ) of the residents in the two neighbourhoods were dissatisfied with government provision of amenities such as elementary schools, hospitals/clinics, police stations and shopping facilities. However, over a quarter of the residents were satisfied with these amenities. Slightly over 40 percent of the residents in the planned neighbourhoods were satisfied with the condition of streets. The satisfaction was as a result of fairly good condition of the Streets.

Table two further revealed that 47.5 percent and 49.4 percent of residents in old GRA and D - Line respectively were satisfied with neighbourhood cleanliness. Slightly over a third of the residents in old GRA were dissatisfied with neighbourhood cleanliness. This could be attributed to the throw away attitude exhibited by most Nigerians. Table 2 further revealed that over half (59\% in old GRA and 59.1 in D - Line) of the respondents were satisfied with the social interaction in the neighbourhoods. The table also revealed that few people were very dissatisfied in terms of social interaction. The study showed that a high percent $(53.9 \%$ in Old GRA and $46.3 \%$ ) of the residents were satisfied with the safety of lives and property in their neighbourhoods.

Table 2 also revealed that a large percent $(66.6 \%)$ of residents in Old GRA were satisfied while 57\%of residents in D-Line were dissatisfied with electricity supply.The dissatisfaction was as a result of the unbearable problem of noise pollution and this was mainly from private generators widely used for electricity generation as a result of irregularity in electricity supply from the Power Holding Company of Nigeria (PHCN). This is the reality in the municipality and requires concerted intervention by government to ameliorate the situation. The incessant power cuts have increased noise pollution in our neighbourhoods and this also poses health risks as a result of the noise and air pollution. This shows that electricity supply is a major problem in the city of Port Harcourt and the country in general. Government should intensify effort to the increase electricity supply. The satisfaction of residents in Old GRA could be as a result fairly regular electricity supply because the government house where the Governor resides is located there. Most residents (64.2\% in Old GRA and 68.8\% in DLine)were satisfied with their neighbourhoods in general as shown in table 2.

Table 2: Satisfaction with Selected Neighbourhood Attributes

\begin{tabular}{|c|c|c|c|c|}
\hline \multirow[t]{2}{*}{ Neighbourhood Attributes } & \multicolumn{2}{|c|}{ OLD GRA } & \multicolumn{2}{|c|}{ D-Line } \\
\hline & NO. & $\%$ & NO. & $\%$ \\
\hline \multicolumn{5}{|c|}{$\begin{array}{c}\text { On the whole, how satisfied are you with government provision } \\
\text { of amenities.. I mean elementary schools, hospitals/clinics, police } \\
\text { stations, and shopping facilities? }\end{array}$} \\
\hline 1. Very Dissatisfied & 20 & 25.6 & 23 & 24.7 \\
\hline 2. Rather Dissatisfied & 18 & 23.1 & 19 & 20.4 \\
\hline 3. Neither Satisfied Nor Dis & 12 & 15.4 & 0 & 0 \\
\hline 4. Fairly Satisfied & 4 & 5.1 & 37 & 39.8 \\
\hline 5. Very Sa & 23 & 29.5 & 11 & 11.8 \\
\hline 6. Missi & 1 & 1.3 & 3 & 3.2 \\
\hline Total & 78 & 100 & 93 & 100 \\
\hline \multicolumn{5}{|c|}{$\begin{array}{l}\text { How satisfied are you with the condition of the streets in this } \\
\text { neighbourhood? }\end{array}$} \\
\hline 1. Very Dissatisfied & 9 & 11.5 & 22 & 23.7 \\
\hline 2. Rather Dissatisfied & 15 & 19.2 & 18 & 19.4 \\
\hline $\begin{array}{l}\text { 3. Neither Satisfied Nor Dissatisfied } \\
\text { 4. Fairly Satisfied }\end{array}$ & 19 & 24.4 & 11 & 11.8 \\
\hline 5. Very Satisfied & 14 & 17.9 & 31 & 33.3 \\
\hline \multirow[t]{2}{*}{ 6. Missing Data } & 19 & 24.4 & 11 & 11.8 \\
\hline & 2 & 2.6 & 0 & 0 \\
\hline & 18 & 100 & 93 & \\
\hline
\end{tabular}

How satisfied are you with the cleanliness of this neighborhood?

\begin{tabular}{|l|c|c|c|c|}
\hline 1. Very Dissatisfied & 14 & 17.9 & 19 & 20.4 \\
\hline
\end{tabular}

\begin{tabular}{|l|c|c|c|c|}
\hline 2. Rather Dissatisfied & 11 & 14.1 & 19 & 20.4 \\
\hline
\end{tabular}

\begin{tabular}{|l|c|c|c|c|}
\hline 3. Neither Satisfied Nor Dissatisfied & 15 & 19.2 & 9 & 9.7 \\
\hline 4. Fairly Satisfied & 18 & 23.1 & 35 & 37.6 \\
\hline
\end{tabular}

\begin{tabular}{|l|c|c|c|c|}
\hline 4. Fairly Satisfied & 18 & 23.1 & 35 & 37.6 \\
\hline
\end{tabular}

\begin{tabular}{|l|c|c|c|c|}
\hline 5. Very Satisfied & 19 & 24.4 & 11 & 11.8 \\
\hline 6.5
\end{tabular}

6. Missing Data

Total

\begin{tabular}{|c|c|c|c|}
\hline 78 & 100 & 93 & 100 \\
\hline
\end{tabular}

what about the level of social interaction in this neighborhood? \begin{tabular}{|l|c|c|c|c|}
\hline 1. Very Dissatisfied & 1 & 1.3 & 11 & 11.8 \\
\hline
\end{tabular}

\begin{tabular}{|l|c|c|c|c|}
\hline 2. Rather Dissatisfied & 14 & 17.9 & 15 & 16.1 \\
\hline $\begin{array}{l}\text { 3. Neither Satisfied Nor } \\
\text { Dissatisfied }\end{array}$ & 16 & 20.5 & 12 & 12.9 \\
\hline 4. Fairly Satisfied & 27 & 34.6 & 20 & 21.5 \\
\hline 5. Very Satisfied & 19 & 24.4 & 35 & 37.6 \\
\hline 6. Missing Data & 1 & 1.3 & 0 & 0 \\
\hline Total & 78 & 100 & 93 & 100 \\
\hline A.
\end{tabular}

And now, I would like to ask about safety. How satisfied are you with the level of safety of property and lives in this neighborhood?

\begin{tabular}{|l|c|c|c|c|}
\hline 1. Very Dissatisfied & 2 & 2.6 & 14 & 15.1 \\
\hline 2. Rather Dissatisfied & 16 & 20.5 & 26 & 28 \\
\hline
\end{tabular}

\section{Volume 6 Issue 1, January 2017




\section{International Journal of Science and Research (IJSR) ISSN (Online): 2319-7064}

Index Copernicus Value (2015): 78.96 | Impact Factor (2015): 6.391

\begin{tabular}{|l|c|c|c|c|} 
3. Neither Satisfied Nor Dissatisfied & 18 & 23.1 & 10 & 10.8 \\
\hline 4. Fairly Satisfied & 12 & 15.4 & 18 & 19.4 \\
\hline 5. Very Satisfied & 30 & 38.5 & 25 & 26.9 \\
\hline 6. Missing Data & 0 & 0 & 0 & 0 \\
\hline Total & 78 & 100 & 93 & 100 \\
\hline
\end{tabular}

How satisfied are you with the electricity supply in this neighborhood?

\begin{tabular}{|l|c|c|c|c|}
\multicolumn{5}{|c|}{ neighborhood? } \\
\hline 1. Very Dissatisfied & 1 & 1.3 & 34 & 36.6 \\
\hline 2. Rather Dissatisfied & 5 & 6.4 & 19 & 20.4 \\
\hline $\begin{array}{l}\text { 3. Neither Satisfied Nor Dissatisfied } \\
\text { 4. Fairly Satisfied }\end{array}$ & 20 & 25.6 & 3 & 3.2 \\
\hline 5. Very Satisfied & 26 & 33.3 & 19 & 20.4 \\
\hline 6. Missing Data & 26 & 33.3 & 18 & 19.4 \\
\hline & 0 & 0 & 0 & 0 \\
\hline Total & 78 & 100 & 93 & 100 \\
\hline
\end{tabular}

On the whole, how satisfied are you with your Neighbourhood?

\begin{tabular}{|l|c|c|c|c|}
\hline 1. Very Dissatisfied & 1 & 1.3 & 11 & 11.8 \\
\hline 2. & 2 & 2.6 & 5 & 5.4 \\
\hline
\end{tabular}

\begin{tabular}{|l|c|c|c|c|}
\hline 2. Rather Dissatisfied & 2 & 2.6 & 5 & 5.4 \\
\hline
\end{tabular}

\begin{tabular}{|l|c|c|c|c|}
\hline 3. Neither Satisfied Nor Dissatisfied & 17 & 21.8 & 10 & 10.8 \\
\hline
\end{tabular}

\begin{tabular}{|l|c|c|c|c|}
\hline 4. Fairly Satisfied & 25 & 32.1 & 36 & 38.7 \\
\hline 5. & 25 & 32.1 & 28 & 30.1 \\
\hline
\end{tabular}

\begin{tabular}{|l|c|c|c|c|}
\hline 5. Very Satisfied & 25 & 32.1 & 28 & 30.1 \\
\hline
\end{tabular}

\begin{tabular}{|l|c|c|c|c|}
\hline 6. Missing Data & 8 & 10.3 & 3 & 3.2 \\
\hline
\end{tabular}

Total

(Source: Author's Field Survey)

\subsection{Sanitation Attributes}

Table 3 displays the results of sanitation attributes. The water closet was found mostly in the two planned neighbourhoods. The study also revealed that few residents in D-Line use the pit and pail toilets. Household garbage was collected from homes and disposed mainly by government agencies and dump mainly in collection points in D-Line. Waste collection and disposal was mostly by private refuse vendors using locally fabricated metal carts in the city. The refuse vendors dump refuse into creeks, drains and roads and this is a major cause of water pollution, flooding and insanitary environment. The blocked drains have become breeding grounds for mosquitoes and subsequently affect the health of residents

The study also revealed that over a third of the residents said that some of the available drains were blocked. This is a critical issue as it can contribute to flooding during the rainy season and it is also a health challenge. Educating the masses on waste management and good sense of environmental management will tackle the problem of insanitary environment to a great extent. Control of development and proper planning will also contribute to tackling the problem.

The main source of water supply was the borehole. Table 3 showed that over a quarter of the residents purchased water from owners of private borehole. The provision of water in the city by the government is minimal. Table 3 revealed that over a third of the residents were dissatified with water supply. It is a primary responsibillity of government to provide this basic service for it citizenry. This is a critical issue and shows that government provision of this basic and important service is virtually nonexistent. This is in line with findings from previous studies. Wokekoro (2005) also established that the main source of water supply was the private borehole in Port Harcourt. This shows that the water supply situation has not improved in the city. In order to ensure public health there must be adequate supply of water. It is unlikely that goal 6 of the Sustainable Development Goals (SDG) will be achieved by the year 2030. SDG 6 urged governments and policy makers to -ensure availability and sustainable management of clean water and sanitation for all by 2030". These conditions were also observed by Ogionwo (1979) and Izeogu (1989), which shows that sanitary condition, has not improved.

Table 3: Sanitation Attributes

\begin{tabular}{|c|c|c|c|c|}
\hline \multirow[t]{2}{*}{ Sanitation Attributes } & \multicolumn{4}{|c|}{\begin{tabular}{l|l|l} 
Old GRA & D Line \\
\end{tabular}} \\
\hline & $\mathrm{N}$ & $\%$ & $\mathrm{~N}$ & $\%$ \\
\hline \multicolumn{5}{|c|}{ Method of sewage (human waste) disposal ie type of toilet } \\
\hline 1 Water closet & 78 & 100 & 86 & 92.5 \\
\hline 2 Pit latrine & 0 & 0 & 4 & 4.3 \\
\hline 3. Pail/ bucket & 0 & 0 & 0 & 0 \\
\hline 4. Bush & 0 & 0 & 0 & 0 \\
\hline 5. Pier waterside & 0 & 0 & 3 & 3.2 \\
\hline 6. No Toilet & 0 & 0 & 0 & 0 \\
\hline 7. Missing Data & 0 & 0 & 0 & 0 \\
\hline Total & \multicolumn{2}{|c|}{78100} & \multicolumn{2}{|c|}{93100} \\
\hline \multicolumn{5}{|l|}{ House Hold Refuse Disposal } \\
\hline 1.Collected by Government Agency & 27 & 34.6 & 8 & 8.6 \\
\hline 2.Collected by Private Arrangement & 20 & 25.6 & 30 & 32.3 \\
\hline 3.Buried & 1 & 1.3 & 0 & 0 \\
\hline 4.Dumped of anywhere in the open & 14 & 17.9 & 0 & 0 \\
\hline 5 Burnt & 1 & 1.3 & 0 & 0 \\
\hline 6. Dumped in collection point. & 13 & 6.7 & 52 & 55.9 \\
\hline 7. Others specify & 2 & 2.6 & 3 & 3.2 \\
\hline 8. Missing Data & 0 & 0 & 0 & 0 \\
\hline Total & 78 & 100 & 93 & 100 \\
\hline \multicolumn{5}{|l|}{ Condition of Drains } \\
\hline 1. Drains Blocked & 25 & 32.1 & 45 & 48.4 \\
\hline 2. Drains Flowing & 38 & 48.7 & 21 & 22.6 \\
\hline 3. No Drains & 14 & 17.9 & 27 & 29 \\
\hline 4. Missing Data & 1 & 1.3 & 0 & 0 \\
\hline Total & 78 & 100 & 93 & 100 \\
\hline \multicolumn{5}{|l|}{ Potable Water Supply } \\
\hline Pipe borne water from public mains. & 21 & 26.9 & 3 & 3.2 \\
\hline Pipe borne water from borehole. & 35 & 44.9 & 53 & 57 \\
\hline Well. & 0 & 0 & 0 & 0 \\
\hline Buy from borehole. & 22 & .28 .2 & 29 & 31.2 \\
\hline Missing data. & 0 & 0 & 8 & 8.6 \\
\hline Total & 78 & 100 & 93 & 100 \\
\hline \multicolumn{5}{|l|}{ Satisfaction with Water Supply } \\
\hline Very Dissatisfied & 3 & 3.8 & 15 & 29 \\
\hline Rather Dissatisfied & 23 & 29.5 & 8 & 16.1 \\
\hline Neither Satisfied Nor Dissatisfied & 7 & 9 & 27 & 8.6 \\
\hline Fairly satisfied & 19 & 24.4 & 16 & 29 \\
\hline Very satisfied & 25 & 32.1 & 16 & 17.2 \\
\hline Missing Data & 1 & 1.3 & 0 & 0 \\
\hline Total & 78 & 100 & 93 & 100 \\
\hline
\end{tabular}

(Source: Author's Field Survey)

\subsection{Neighbourhood Satisfaction Index}

The neighbourhood satisfaction index showed that most residents (62.8\%) in Old GRAwere moderately satisfied with their neighbourhood while $45.2 \%$ of the residents were moderately satisfied in D-Line.However, $23.1 \%$ of the residents in Old GRA were highly satisfied while slightly over a third of the residents are highly satisfied with their neighbourhood condition as a whole. (See table 4)

\section{Volume 6 Issue 1, January 2017 www.ijsr.net}




\section{International Journal of Science and Research (IJSR) \\ ISSN (Online): 2319-7064}

Index Copernicus Value (2015): 78.96 | Impact Factor (2015): 6.391

Table 4: Neighbourhood Satisfaction Index

\begin{tabular}{|c|c|c|c|c|}
\hline \multirow{2}{*}{ Quality } & \multicolumn{2}{|c|}{ Old GRA } & \multicolumn{2}{c|}{ D-Line } \\
\cline { 2 - 5 } & $N$ & $\%$ & $N$ & $\%$ \\
\hline Low (1) & 1 & 1.3 & 18 & 19.4 \\
\hline Medium (2) & 49 & 62.8 & 42 & 45.2 \\
\hline High (3) & 18 & 23.1 & 30 & 32.3 \\
\hline Missing & 10 & 12.8 & 3 & 3.2 \\
\hline Total & $\mathbf{7 8}$ & $\mathbf{1 0 0}$ & $\mathbf{9 3}$ & $\mathbf{1 0 0}$ \\
\hline
\end{tabular}

(Source: Author's Field Survey)

\subsection{Perceived Residential Quality of Life}

Table 5 captures the perception of residential quality of life in the study area with some of the respondents reporting a positive quality. Specifically, $25.6 \%$ of the residents in Old GRA and $14 \%$ in D- Line were pleased with their neighbourhood conditions while few $(7.7 \%$ in Old GRA and $10.8 \%$ in D-Line) perceived their residential environment as terrible. Only $19.2 \%$ of residents in Old GRA were delighted with their residential environment while $11.9 \%$ were delighted with their environment in D-line.

Table 5: Perceived Residential Quality of Life

\begin{tabular}{|c|c|c|c|c|}
\hline & \multicolumn{2}{|c|}{ Old GRA } & \multicolumn{2}{|c|}{ D-Line } \\
\hline Residential Quality of Life as a whole & $\mathrm{N}$ & $\%$ & $\mathrm{~N}$ & $\%$ \\
\hline 1.Terrible & 6 & 7.7 & 10 & 10.8 \\
\hline 2.Unhappy & 22 & 28.2 & 6 & 6.5 \\
\hline 3.Mostly dissatisfied & 2 & 2.6 & 4 & 4.3 \\
\hline 4.Mixed & 12 & 15.4 & 9 & 9.7 \\
\hline 5.Mostly satisfied & 1 & 1.3 & 37 & 39.8 \\
\hline 6.Pleased & 20 & 25.6 & 13 & 14 \\
\hline 7.Delighted & 15 & 19.2 & 11 & 11.8 \\
\hline 8.Missing data & 0 & 0 & 3 & 3.2 \\
\hline Total & 78 & 100 & 93 & 100 \\
\hline
\end{tabular}

(Source: Authors' Field Survey, 2011)

\section{Conclusion}

In this study residents' satisfaction with the neighbourhood quality in the planned neighbourhoods in Port Harcourt was examined. The study concludes that high percentage of residents across the two neighbourhoods were satisfied with cleanliness of the neighbourhood, safety of lives and properties, residential planning, provision of basic amenities, hospitals/clinics, fire stations, police stations, waste collection and disposal. The study further reveals that most residents were satisfied with public schools, and shopping facilities.

The study concludes that some residents were dissatisfied with their residential conditions such as electricity supply, water supply and waste collection and disposal in these neighbourhoods. The study further revealed that $25.6 \%$ of the residents in Old GRA were pleased with their residential quality of life and $14 \%$ of the residents were pleased with their residential quality of life in D-Line. The study further concluded that in the provision of public infrastructure and services, the perceptions and preferences of the beneficiaries/target population must be seriously taken into account to achieve user satisfaction. The study has shown that some respondents were not satisfied with their neighbourhood conditions. The study recommended that the government should take advantage of funds available in the
National Urban Development Bank, assistance from international development agencies and through privatepublic-partnership (PPP) arrangements to maintain and provide adequate infrastructure and amenities.

\section{References}

[1] Adewale, B.A., Taiwo, A. A., Izobo-Martins, O.O. and Ekhaese, E.N. (2015). Age of Residents and Satisfaction with the Neighbourhood in Ibadan Core Area: A Case Study of Oke Foko. Global Journal of Arts Humanities and Social Sciences,3(2),52-61.

[2] Andrews, F. M. (1980). Subjective Social Indicators, Objective Social Indicators, and Social Accounting Systems. Survey Research Centre, The University of Michigan, Ann Arbor, USA.

[3] Coker, A.O, Awokola, O.S., Olomolaiye, P. O., and Booth, C. A. (2007). Challenges of urban Housing Quality and its Associations with Neighbourhood Environments: insights and experiences of Ibadan City,Nigeria.Chartered Institute of Environmental Health www.cieh.org Accessed 16/ 7/ 09

[4] Discoli, Rosenfeld, Juan,s., Martini, Barbero, Ferreyro,and Dicroce (2006).-UUrban Integration and Disintegration Forces: The habitants/Users Perception in an Urban life Quality Model for the Surroundings of LaPlata, Buenos Aires, Argentina."A paper presented at the $42^{\text {nd }}$ International Society of City and Regional Planners (IsoCARP) Congress, 2006.

[5] Giannias, D. A (1996).Quality of Life in Southern Ontario. Department of Economics,University of Crete, Athens Greece. www.findarticles.com Accessed $15 / 5 / 11$

[6] Hall,L.J. , Madrigal,R. and Robalino, J.(2008). "Quality of Life in Urban Neighborhoods in Costa Rica", InterAmerican Development Bank, Latin American Research Network, Research Network Working Paper www.iadb.org/res/publications/pubfiles\#R-563. Accessed 16/7/09

[7] Hebert Research (2009). Resident Satisfaction Survey, Seattle Housing Authority, Bellevue, WA. www.seattlehousing.org

[8] Jongudomkarn, D. and Camfield, L.(2005). Exploring The Quality of Life ofPeople in North Eastern And southern Thailand" WeD Working Paper11www.welldev.org.ukAccessed 16/ 7/ 09

[9] Kehinde,O.J., Ojo,T.I. and Oginni,E.O.(2015).Residents' Satisfaction in Public Estates in Osogbo, Nigeria.Merit Research Journal of Art, Social Science and Humanities,3(1),010-017.

[10]Kish, L. (1965). Survey Sampling. John Willey and Sons Inc. New York.643pp.

[11]Lotfi, S. and Solaimani, k.(2009). An assessment of Urban Quality of Life by Using Analytic Hierarchy Process Approach(Case study: Comparative Study of Quality of Life in the North of Iran)" Journal of Social Sciences 5(2):123-133.

[12]Marans, R. W. (!979). The Determinants of Neighbourhood Quality: An Analysis of the 1976 Annual Housing Survey. A Report Prepared for the U.S. Department of Housing and Urban Development, Office of Policy Development and Research.

\section{Volume 6 Issue 1, January 2017




\section{International Journal of Science and Research (IJSR) \\ ISSN (Online): 2319-7064}

Index Copernicus Value (2015): 78.96 | Impact Factor (2015): 6.391

[13] Mchi, A.A. (1997). Assessing Residential Environmental Quality withinSelected Resid ential Areas of Port Harcourt." Unpublished B.Tech Project. Department of Urban \& Regional Planning, Rivers State University Science \& Technology, Port Harcourt.

[14] Melnick,D., McNeely, J. , Navarro,Y.K., SchmidtTraub, G. and Sears, R. R.(2005).Environment and Human Wellbeing: a Practical Strategy. UN Millenium Project. Earthscan, London. 133pp.

[15] Mridha, A. and Moore, G. T.(2011)The Quality of Life in Dhaka, Bangledesh: Neighborhood Quality as a Major Component of Residential Satisfaction. www.researchgate.net Doi 10. 1007/978-94-007-1742$8 \_11$

[16] Novianto, D.,Gao, W., Kuroki, S. and Fukahori, H. (2016) Statistical Evaluation on Neighbourhood Facilities in Relation with Residential Satisfaction and Preference. American Journal of Environmental Sciences.12(3),169-181

[17] Obinna, V.C., Owei, O. B. and Mark, E.O.(2010). fnformal Settlements of Port Harcourt and Potentials For Planned City Expansion.” Environmental Research Journal Vol.4, No. 3, pp 222-228.

[18] Ogionwo, W. (1979). A Social Survey of Port Harcourt. Heinemann Educational Books (Nig.) Ltd, Enugu. 273 Pp.

[19] Pacione, M. (2003). Urban Environmental Quality and Human Wellbeing-A Social Geographical Perspective." Landscape and Urban Planning 65. pp.19-30.

[20] Salau, A. T. (1986). Quality of life and city size: An exploratory study of Nigeria."Social Indicators Research Vol.18, No.2 pp.193-203

[21] Senecal,G.(2002). Urban Spaces and Quality of Life: Moving Beyond Normative Approaches", http://policyresearch.Gc.Ca/page.Asp? Pagenm $=v s n l$ art-06Accessed 18/12/2002

[22] Ugwuorah, A. N. (2002). The Relevance of the Urban and Regional Law (Decree. 88 of 1992) to Environmental Management in Port Harcourt Metropolis.” Unpublished M. Phil. Thesis, Department of Environmental Management, Institute of Geosciences and Space Technology, RSUST, Port Harcourt.

[23] UNHSP (2008). The State of African Cities, A framework For Addressing Urban Challenges in Africa.UN Habitat. Nairobi, Kenya. 206pp.

[24] WHO-IASSID WORK PLAN (2000). Quality of Life its Conceptualization Measurements and Application. .A Consensus Document. The Special Interest Research Group on Quality of Life. The International Association for the Scientific Study of Intellectual Disabilities. www.beachcenter.org/boards/fullpublications Accessed $11 / 7 / 2008$.

[25] Wokekoro, E. and Owei, O.B.(2006). Environmental Indicators of Derelict Housing in Nigerian Cities case Study of Port Harcourt, Rivers State." A Paper Presented at the International Conference on Infrastructure Development and the Environment (ICIDEN), Abuja Nigeria. September 10 - 15, 2006.

[26] Yamane, T. (1967). Statistics, an Introductory Analysis $2^{\text {nd }}$ ed., Harper and Row, New York. 919pp

Volume 6 Issue 1, January 2017

www.ijsr.net 